\title{
The Effect of Dehydroepiandrosterone (DHEA) Supplementation on IVF or ICSI: A Meta-Analysis of Randomized Controlled Trials
}

\author{
Auswirkungen der Dehydroepiandrosteron-(DHEA-) \\ Supplementierung auf IVF oder ICSI: eine Metaanalyse \\ von randomisierten kontrollierten Studien
}

(C) 98

Authors

Lin $\mathrm{Xu}{ }^{1}$, Chunxia Hu${ }^{2}$, Qun Liu ${ }^{1}$, Yaxuan $\mathrm{Li}^{1}$

\section{Affiliations}

1 Department of reproductive medicine, First Affiliated

Hospital of Hainan Medical College, Haikou, Hainan

570102, China

2 Department of Obstetrics, First Affiliated Hospital of

Hainan Medical University, Haikou, Hainan 570102, China

Key words

dehydroepiandrosterone (DHEA), diminished ovarian reserve (DOR), poor ovarian response (POR), in vitro fertilization (IVF), intracytoplasmic sperm injection (ICSI)

Schlüsselwörter

Dehydroepiandrosteron (DHEA), eingeschränkte ovarielle Reserve (DOR), schlechte ovarielle Reaktion (POR), In-vitroFertilisation (IVF), intrazytoplasmatische Spermieninjektion (ICSI)

received 4.1.2019

revised 20.3.2019

accepted 22.3.2019

Bibliography

DOI https://doi.org/10.1055/a-0882-3791

Geburtsh Frauenheilk 2019; 79: 705-712 @ Georg Thieme

Verlag KG Stuttgart · New York | ISSN 0016-5751

Correspondence

Lin Xu

Department of reproductive medicine, First Affiliated Hospital of Hainan Medical College

No. 31 Longhua Road, Haikou, Hainan 570100, China

xulinmumu@163.com

\begin{abstract}
Introduction A systematic review and meta-analysis were conducted to evaluate the efficacy of dehydroepiandrosterone (DHEA) supplementation in patients with diminished ovarian reserve (DOR) and/or poor ovarian response (POR) who were undergoing in vitro fertilization or intracytoplasmic sperm injection (IVF/ICSI).

Patients and Methods We searched the PubMed, EMBASE, Web of Science, and Cochrane Library electronic databases for literature published until july 2018. The analysis included randomized controlled trials (RCTs) of the effects of DHEA versus placebo on IVF or ICSI. Two independent reviewers extracted information from the reports and evaluated the quality of the studies. Overall, we identified nine prospective RCTs involving 833 patients.
\end{abstract}

Results Compared to the controls, patients treated with DHEA exhibited increases in the number of retrieved oocytes (mean difference, 0.91; 95\% confidence interval [Cl], 0.231.59; $\mathrm{p}=0.009$ ), clinical pregnancy rate (relative risk $[R R]=1.27 ; 95 \% \mathrm{Cl}, 1.01-1.61 ; p=0.04)$, and live birth rate (RR, 1.76; 95\% Cl, 1.17-2.63; $p=0.006)$. However, there was no intergroup difference in the miscarriage rate ( $R R, 0.37$; $95 \% \mathrm{Cl}, 0.12-1.13 ; \mathrm{p}=0.08)$.

Conclusion DHEA supplementation improved the outcomes of IVF/ICSI in women with DOR or POR.

\section{ZUSAMMENFASSUNG}

Einleitung Es wurde eine systematische Überprüfung und eine Metaanalyse durchgeführt, um die Wirksamkeit der Dehydroepiandrosterone-(DHEA-)Supplementierung zu bewerten bei Patientinnen mit eingeschränkter ovarieller Reserve (DOR) und/oder unzureichender ovarieller Reaktion (POR), die sich einer In-vitro-Fertilisation bzw. einer intrazytoplasmatischen Spermieninjektion (IVF/ICSI) unterzogen.

Patientinnen und Methoden In einer Literaturrecherche wurde in den elektronischen Datenbanken von PubMed, EMBASE, Web of Science und der Cochrane Library nach Literatur gesucht, die vor Juli 2018 zu diesem Thema veröffent- 
licht worden war. In die Analyse aufgenommen wurden randomisierte kontrollierte Studien (RCTs), welche die Auswirkungen von DHEA auf IVF und ICSI mit Placebo verglichen. Die Studiendaten wurden von 2 unabhängigen Beurteilern gesammelt, die auch die Qualität der jeweiligen Studien evaluierten. Insgesamt konnten wir 9 prospektive RCTs mit insgesamt 833 Patientinnen ausfindig machen.

Ergebnisse Verglichen mit den jeweiligen Kontrollgruppen, nahm bei den mit DHEA behandelten Patientinnen die Anzahl gewonnener Eizellen zu (Mittelwertdifferenz, 0,91; 95\%-Kon- fidenzintervall [KI], 0,23-1,59; $\mathrm{p}=0,009)$; die klinische Schwangerschaftsrate (relatives Risiko $[R R]=1,27$; 95\%-KI, $1,01-1,61 ; p=0,04)$ und die Lebendgeburtenrate (RR, 1,76; $95 \%-K I, 1,17-2,63 ; p=0,006)$ nahmen ebenfalls zu. Es gab aber keine Differenz zwischen den Gruppen in Bezug auf die Fehlgeburtenrate (RR, 0,37; 95\%-KI, 0,12-1,13; $\mathrm{p}=0,08$ ).

Schlussfolgerung Die DHEA-Supplementierung trug zu einer Verbesserung des Outcomes nach IVF/ICSI bei Frauen mit DOR oder POR bei.

\section{Introduction}

The increasing pace of social life and postponement of childbearing have led to widespread subfertility, which is estimated to affect $10-15 \%$ of couples of reproductive age [1,2]. A diminished ovarian reserve (DOR), also known as age-related infertility, refers to smaller follicles and a reduced ovarian follicular pool size at a given age [3]. DOR is an indicator of ovarian aging, which is associated with reductions in the quantity and quality of oocytes within the ovaries [4,5]. Ovarian aging is also associated with a decline in fertility [6-9] and an increase in adverse pregnancy outcomes, such as miscarriage $[10,11]$. Moreover, DOR causes poor responses to ovarian stimulation. Accordingly, patients with DOR have a low pregnancy rate, high cancellation rate, and high miscarriage rate during assisted reproductive technology (ART) [12]. Given the widespread application of in vitro fertilization-intracytoplasmic sperm injection (IVF-ICSI), the management of poor ovarian responders presents a significant clinical challenge $[13,14]$.

Dehydroepiandrosterone (DHEA) is an endogenous steroid secreted from the reticularis zona of the adrenal cortex and ovarian theca cells [15], the latter of which play an essential role in ovarian follicular steroidogenesis [16]. Although recent randomized controlled trials (RCT) and meta-analyses have evaluated the efficiency and safety of DHEA in women with DOR, the conclusions have not been consistent [17-24]. Therefore, this meta-analysis aimed to screen the literature and extract the results of randomized controlled trials (RCTs) that investigated the efficacy of DHEA supplements in women with DOR and/or poor ovarian response (POR) who underwent IVF or ICSI.

\section{Methods}

\section{Literature search and screening}

Two independent authors (XL and HCX) systematically searched the PubMed, EMBASE, and Web of Science databases for literature published from inception to July 1, 2018. The following keywords were used: "Dehydroepiandrosterone" or "DHEA"; and/or "Diminished ovarian reserve" or "Premature ovarian aging" or "Poor response" or "Low response"; and/or "Randomized controlled trial" or "RCTs". We limited the search to articles published in English. We also manually screened the reference lists of the retrieved articles to identify additional studies.

\section{Inclusion and exclusion criteria}

The inclusion criteria were

1. RCTs;

2. an intervention of DHEA versus control in women with DOR and/or POR who were undergoing IVF or ICSI;

3. and a report of at least one of the following outcomes: clinical pregnancy rate, live birth rate, miscarriage rate, or retrieved oocytes.

The exclusion criteria were

1. non-English language publications;

2. animal studies, reviews, commentaries, letters, or single case studies; or

3. an inability to extract data from the study.

\section{Data extraction and quality assessment}

Two investigators (LQ and LYX) independently extracted data from each study, including the first author, year, country, sample size, patient age, interventions, clinical pregnancy rate, live birth rate, miscarriage rate, and retrieved oocytes. Two reviewers (LQ and LYX) independently used the Cochrane Collaboration tool to assess the quality of the included studies [25]. We evaluated the risk of bias using the following parameters: random sequence generation, allocation concealment, blinding, incomplete outcome data, free of selective reporting, and other bias. We resolved disagreements through discussion and consultation with the third author $(\mathrm{XL})$ as needed.

\section{Statistical analysis}

We used RevMan 5.2 (Cochrane Collaboration) to perform a meta-analysis using fixed and random effect models based on heterogeneity. Dichotomous results were analyzed by calculating the relative risks (RRs) with $95 \%$ confidence intervals (Cls). We summarized the continuous data for each unit of analysis by calculating the mean differences (MDs) with 95\% Cls. We used Cochran's Q and the $\mathrm{I}^{2}$ statistic to evaluate heterogeneity between the studies. We applied a random effects model if significant heterogeneity was identified between studies $\left(p<0.1, I^{2}>50 \%\right)$. Otherwise, we applied a fixed effect model. A funnel plot was used to evaluate publication bias. 


\section{Results}

\section{Study characteristics and quality assessment}

- Fig. 1 shows the flow diagram of the study selection process. We identified 862 studies during the initial search. Of these, we excluded 326 duplicates and 528 irrelevant articles after reading the titles and abstracts. Of the remaining 18 articles, we excluded 9 for the reasons described in $\mathbf{F i g}$. 1. Finally, we included 9 RCTs [26-34]. - Table 1 summarizes the characteristics of each included study. All nine studies were published between 2010 and 2017. The sample sizes ranged from 24 to 208, with a total of 862 patients. All of the included patients had been diagnosed with DOR and/or poor ovarian response (POR). The treatment intervention was $75 \mathrm{mg}$ daily DHEA versus placebo. Of the nine included studies, six reported retrieved oocytes [26, 28, 31-34], eight reported the clinical pregnancy rate [26-32,34], five reported the live birth rate $[26,28,30,32,34]$, and three reported the miscarriage rate $[26,28,30]$. $~ T$ Table 2 presents the quality assessments of the studies included in the meta-analysis.

\section{Retrieved oocytes}

As shown in > Fig. 2, six studies [26, 28, 31 - 34] including 588 patients (289 in the DHEA group and 299 in the control group) reported retrieved oocytes. Significant heterogeneity was detected among these studies $\left(I^{2}=53 \% ; \mathrm{P}=0.06\right)$. A pooled analysis using the random effects model revealed a statistically significant in-
862 of records identified through database searching

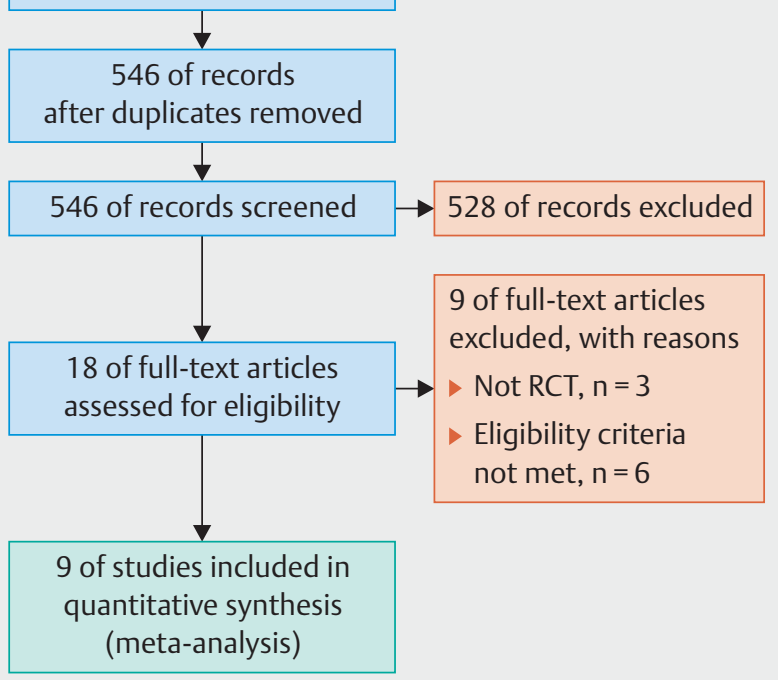

- Fig. 1 Search strategy of study selection of the randomized controlled trials included in this meta-analysis.

- Table 1 Characteristics of the studies included in the review.

\begin{tabular}{|c|c|c|c|c|c|c|}
\hline \multirow{2}{*}{$\begin{array}{l}\text { First author } \\
\text { (Year) }\end{array}$} & \multirow[t]{2}{*}{ Country } & \multirow[t]{2}{*}{ Methods } & \multirow[t]{2}{*}{ Interventions } & \multicolumn{2}{|c|}{ Patients (n) } & \multirow{2}{*}{$\begin{array}{l}\text { Outcomes included } \\
\text { in the meta-analysis }\end{array}$} \\
\hline & & & & DHEA & Controls & \\
\hline $\begin{array}{l}\text { Narkwichean } \\
\text { (2017) }\end{array}$ & $\begin{array}{l}\text { United } \\
\text { Kingdom }\end{array}$ & $\begin{array}{l}75 \mathrm{mg} \text { DHEA daily for at least } \\
12 \text { weeks/matched placebo }\end{array}$ & IVF & 27 & 25 & $\begin{array}{l}\text { Clinical pregnancy rate, live } \\
\text { birth rate, miscarriage rate }\end{array}$ \\
\hline Kotb (2016) & Egypt & $\begin{array}{l}25 \mathrm{mg} \text { DHEA three times } \\
\text { daily for } 12 \text { weeks/matched } \\
\text { placebo }\end{array}$ & IVF & 70 & 70 & $\begin{array}{l}\text { Clinical pregnancy rate, } \\
\text { retrieved oocytes }\end{array}$ \\
\hline Tartagni (2015) & Italy & $\begin{array}{l}75 \mathrm{mg} \text { of DHEA once a day/ } \\
\text { matched placebo }\end{array}$ & IVF/ICSI & 53 & 56 & $\begin{array}{l}\text { Clinical pregnancy rate, live } \\
\text { birth rate, miscarriage rate, } \\
\text { retrieved oocytes }\end{array}$ \\
\hline Zhang (2014) & China & $\begin{array}{l}\text { DHEA } 75 \text { mg daily/matched } \\
\text { placebo }\end{array}$ & IVF & 42 & 42 & Clinical pregnancy rate \\
\hline Yeung (2014) & China & $\begin{array}{l}25 \mathrm{mg} \text { DHEA three times } \\
\text { daily/matched placebo }\end{array}$ & IVF/ICSI & 16 & 16 & $\begin{array}{l}\text { Clinical pregnancy rate, } \\
\text { live birth rate }\end{array}$ \\
\hline Kara (2014) & Turkey & $\begin{array}{l}75 \mathrm{mg} \text { DHEA daily for } \\
12 \text { weeks/matched placebo }\end{array}$ & IVF/ICSI & 104 & 104 & $\begin{array}{l}\text { Retrieved oocytes, } \\
\text { clinical pregnancy rate }\end{array}$ \\
\hline Moawad (2012) & Egypt & $\begin{array}{l}75 \text { mg DHEA daily for } \\
12 \text { weeks/matched placebo }\end{array}$ & IVF & 67 & 66 & $\begin{array}{l}\text { Retrieved oocytes, } \\
\text { clinical pregnancy rate, } \\
\text { live birth rate }\end{array}$ \\
\hline Artini (2012) & Italy & $\begin{array}{l}25 \mathrm{mg} \text { DHEA three times } \\
\text { daily/matched placebo }\end{array}$ & IVF/ICSI & 12 & 12 & Retrieved oocytes \\
\hline Wiser (2010) & Israel & $\begin{array}{l}75 \text { mg DHEA daily } \\
\text { for } \geq 16-18 \text { weeks }\end{array}$ & IVF & 26 & 25 & $\begin{array}{l}\text { Retrieved oocytes, clinical } \\
\text { pregnancy rate, live birth } \\
\text { rate, miscarriage rate }\end{array}$ \\
\hline
\end{tabular}




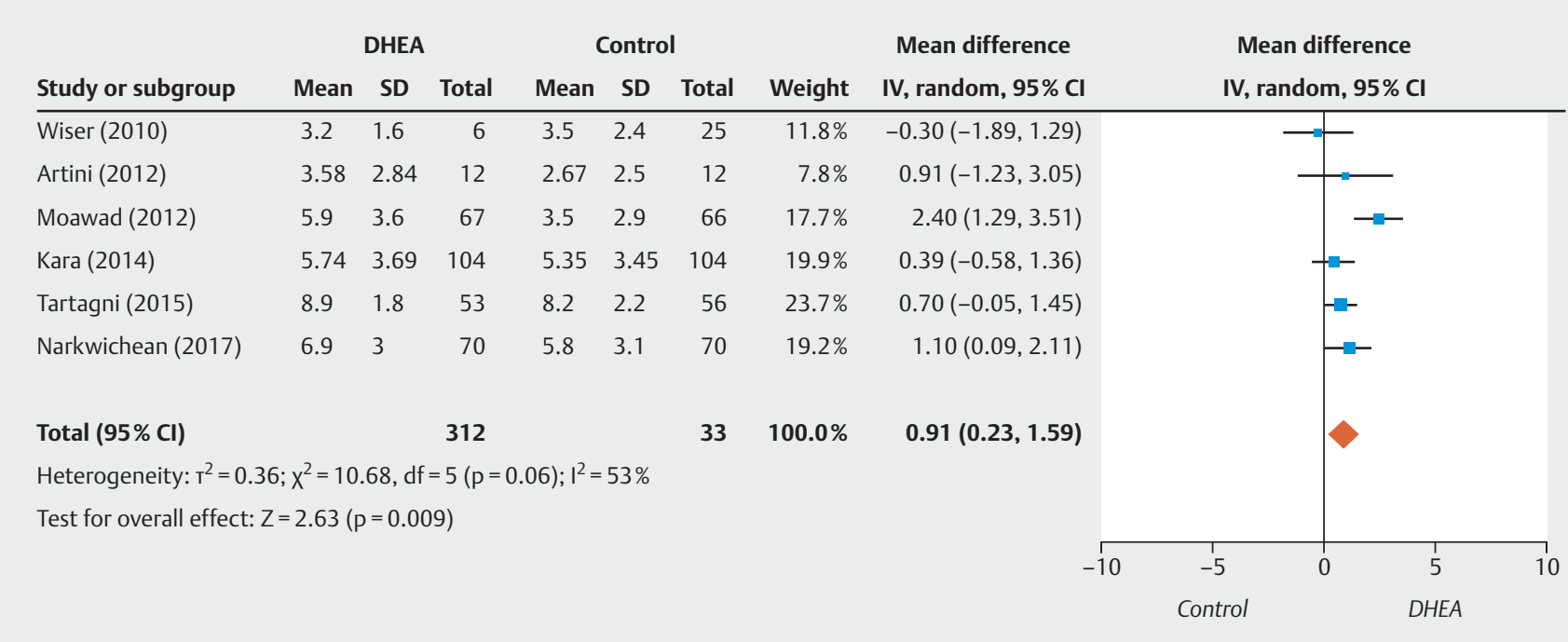

- Fig. 2 Meta-analysis of studies of DHEA supplementation versus controls for outcome of numbers of oocytes retrieved in DOR or poor responders undergoing IVF or ICSI cycle.

- Table 2 Quality assessment of the included studies.

\begin{tabular}{|c|c|c|c|c|c|c|c|}
\hline Author (year) & $\begin{array}{l}\text { Random } \\
\text { sequence } \\
\text { generation }\end{array}$ & $\begin{array}{l}\text { Allocation } \\
\text { concealment }\end{array}$ & $\begin{array}{l}\text { Blinding of } \\
\text { participants } \\
\text { and personnel }\end{array}$ & $\begin{array}{l}\text { Blinding } \\
\text { of outcome } \\
\text { assessment }\end{array}$ & $\begin{array}{l}\text { Incomplete } \\
\text { outcome } \\
\text { data }\end{array}$ & $\begin{array}{l}\text { Selective } \\
\text { reporting }\end{array}$ & Other bias \\
\hline $\begin{array}{l}\text { Narkwichean } \\
\text { (2017) }\end{array}$ & Yes & Yes & Yes & Yes & Unclear & Unclear & Unclear \\
\hline Kotb (2016) & Yes & Yes & Unclear & Unclear & Yes & Unclear & Unclear \\
\hline $\begin{array}{l}\text { Tartagni } \\
\text { (2015) }\end{array}$ & Yes & Yes & Yes & Yes & Unclear & Unclear & Unclear \\
\hline Zhang (2014) & Yes & Unclear & Unclear & Unclear & Yes & Unclear & Unclear \\
\hline Yeung (2014) & Yes & Unclear & Unclear & Unclear & Yes & Unclear & Unclear \\
\hline Kara (2014) & Yes & Unclear & Unclear & Unclear & Yes & Unclear & Unclear \\
\hline $\begin{array}{l}\text { Moawad } \\
(2012)\end{array}$ & Yes & Yes & Yes & Unclear & Unclear & Unclear & Unclear \\
\hline Artini (2012) & Yes & Yes & Yes & Yes & Unclear & Unclear & Unclear \\
\hline Wiser (2010) & Yes & Yes & Yes & Yes & Yes & No & Unclear \\
\hline
\end{tabular}

crease in retrieved oocytes in the DHEA group, compared to the control group (MD, 0.91; 95\% Cl, 0.23-1.59; $\mathrm{p}=0.009$ ).

\section{Clinical pregnancy rate}

Eight studies [26-32,34] including 820 patients (405 in the DHEA group and 415 in the control group) reported the clinical pregnancy rate. As no heterogeneity was identified $\left(\mathrm{I}^{2}=0 \%\right.$; $p=0.57$ ), a fixed-effect model was applied. As shown in > Fig. $\mathbf{3}$, the meta-analysis indicated a statistically significant increase in the clinical pregnancy rate in the DHEA group compared to the control group $(R R=1.27 ; 95 \% C l, 1.01-1.61 ; p=0.04)$.

\section{Live birth rate}

Five studies [26, 28, 30, 32, 34] reported the live birth rate for 379 patients (189 in the DHEA group and 190 in the control group). As no heterogeneity was observed between the studies $\left(\mathrm{I}^{2}=0 \%\right.$; $p=0.43$ ), a fixed-effect model was used. The meta-analysis indicated a statistically significant increase in the live birth rate in the DHEA group, compared to the control group (RR, 1.76; $95 \% \mathrm{Cl}$, 1.17-2.63; $p=0.006$ ), as shown in > Fig. 4 .

\section{Miscarriage rate}

As shown in $>$ Fig. 5, three studies $[26,28,30]$ including 195 patients (96 in the DHEA group and 99 in the control group). reported miscarriage rates. The meta-analysis revealed low hetero- 


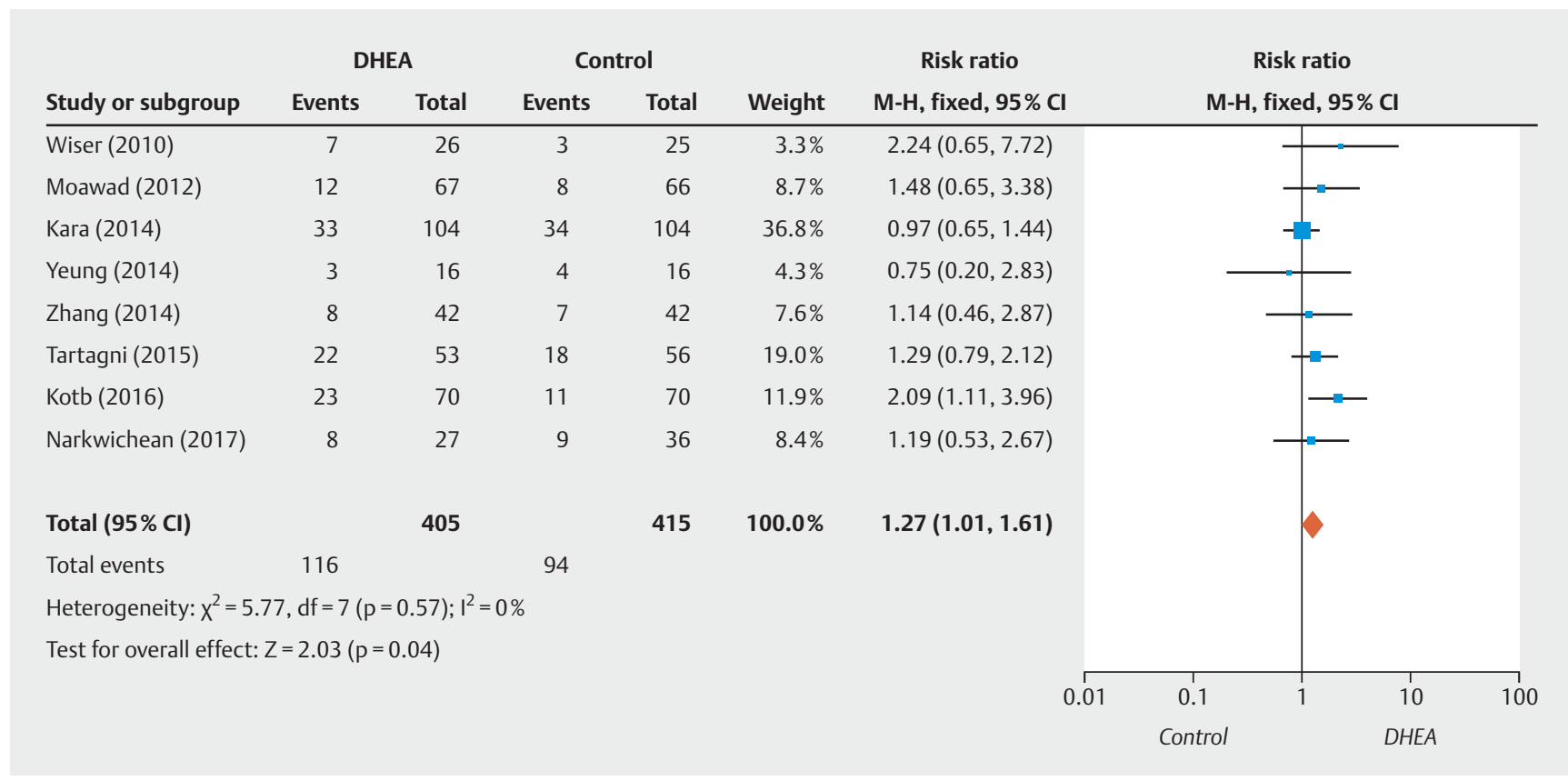

- Fig. 3 Meta-analysis of studies of DHEA supplementation versus controls for outcome of clinical pregnancy rate in DOR or poor responders undergoing IVF or ICSI cycle.

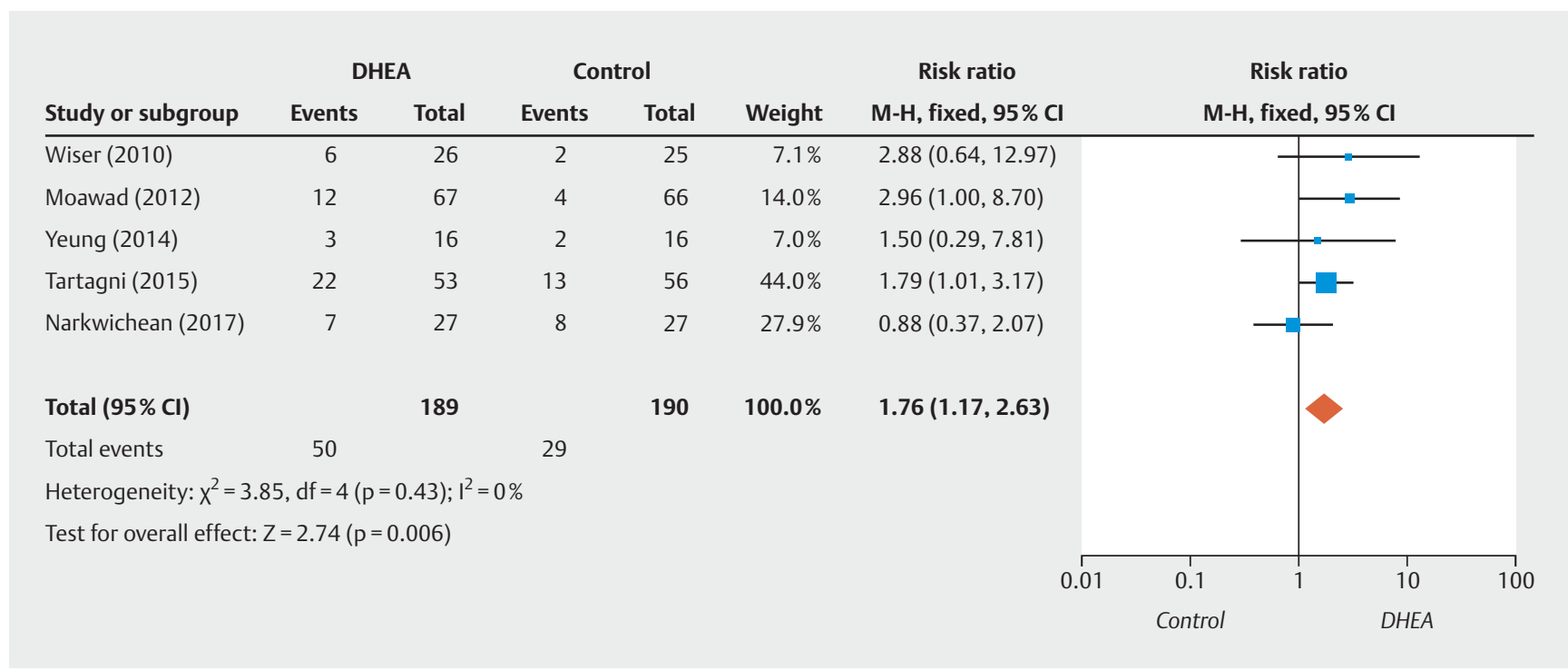

- Fig. 4 Meta-analysis of studies of DHEA supplementation versus controls for outcome of live birth rate in DOR or poor responders undergoing IVF or ICSI cycle.

geneity among the studies $\left(I^{2}=25 \% ; \mathrm{p}=0.26\right)$, and a pooled analysis was conducted using the fixed-effects model. This analysis indicated no significant difference in the miscarriage rates between the DHEA and control groups (RR, 0.37; $95 \% \mathrm{Cl}, 0.12-1.13$; $p=0.08)$.

\section{Publication bias}

Funnel plots were used to determine the potential publication bias. As shown in $\mathbf{F}$ Fig. $\mathbf{6}$, the funnel plot for the outcome of the pregnancy rate was partially symmetrical. The lack of significant asymmetry indicated the lack of potential publication bias in the included studies. 


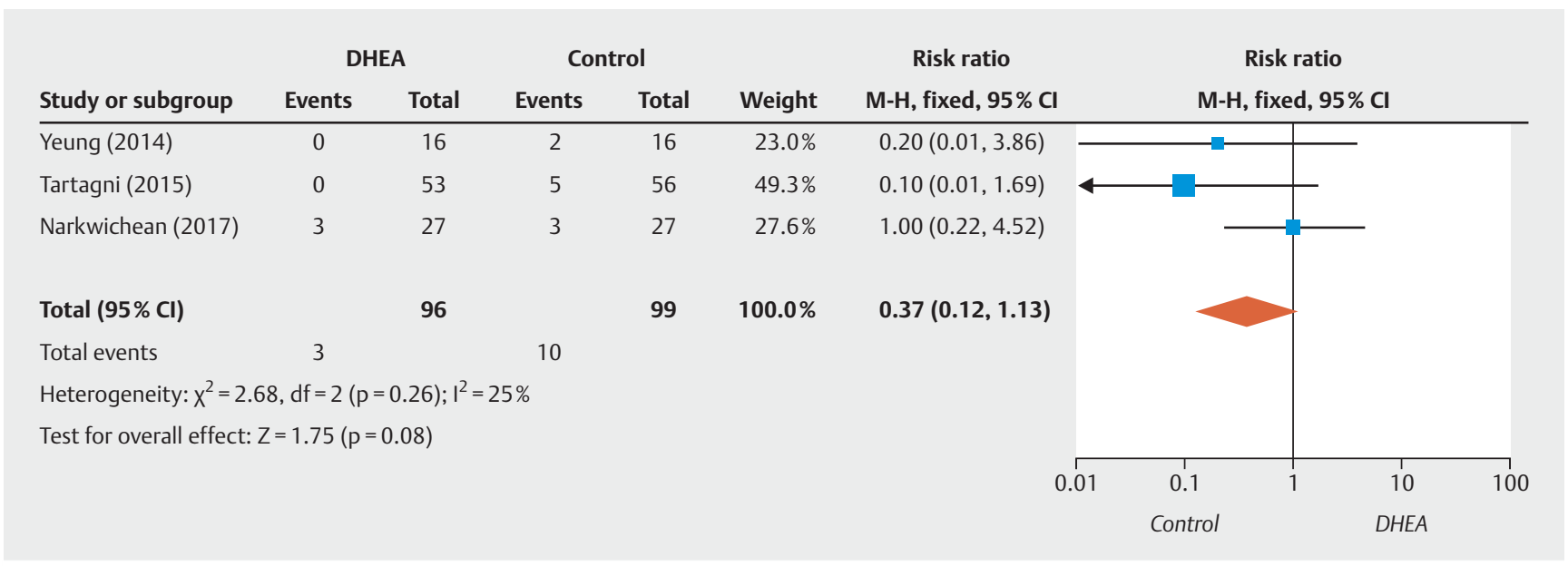

- Fig. 5 Meta-analysis of studies of DHEA supplementation versus controls for outcome of miscarriage rate in DOR or poor responders undergoing IVF or ICSI cycle.

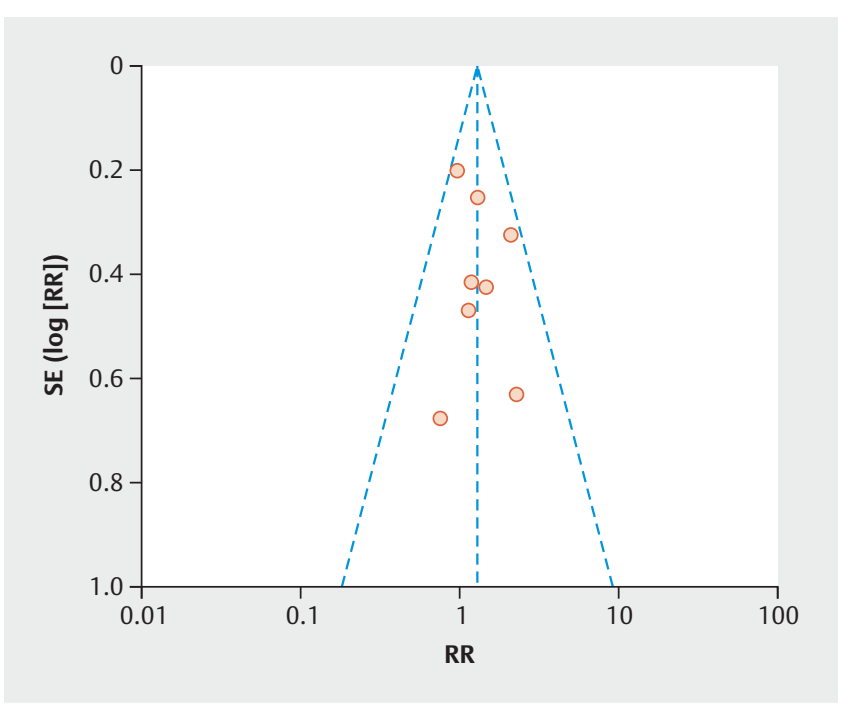

- Fig. 6 Funnel plot of the studies represented in our meta-analysis.

\section{Discussion}

Subfertility is usually associated with DOR and/or POR and is attributed to the accelerated pace of social progress and delayed age of childbearing [35]. However, women with DOR and/or POR usually produce a suboptimal number of oocytes and lower-quality embryos, which consequently reduce the rates of implantation and pregnancy [35]. In recent years, various efforts, including DHEA supplementation, have been made to improve the outcomes of pregnancy in women with DOR and/or POR. However, clinicians have not yet determined precisely the real effect of DHEA on these patients.

Therefore, we performed a meta-analysis to assess the effect of DHEA supplementation on the outcomes of IVF or ICSI in women with DOR and/or POR. We included two studies [26,27] conducted during the 2-year period since the previous meta-analysis
$[19,21]$. The clinical utility of previous meta-analysis was unclear due to that included RCTs, prospective cohort study, or case-control or self-controlled studies, which led to an increased risk of bias. This meta-analysis described herein included nine RCTs, and the results strongly indicated that the DHEA supplementation results significantly increased the clinical pregnancy rate, live birth rate, and number of retrieved oocytes in women with DOR and/ or POR who underwent IVF or ICSI. Additionally, no adverse events related to DHEA were reported $[28,31,34]$, and our results indicated that the miscarriage rate did not differ significantly between the DHEA and control groups.

Several observational studies of women with reduced ovarian reserve or POR have indicated increased ovarian responses and improved pregnancy outcomes after treatment with DHEA [16, $36-39]$. Other studies have reported that DHEA levels decrease with age [40]. One previous study suggested that a lower functional ovarian reserve was associated with androgen deficiency; therefore, DHEA supplementation should improve the functional ovarian reserve [41]. We speculate that DHEA might affect ovarian follicular growth not only by serving as a ligand for androgen receptors, but also by acting as a metabolic precursor for steroid production [42]. Additionally, DHEA can influence follicular growth and improve oocyte quality by mediating an increase in insulin growth factor 1 production $[16,43]$. DHEA was further found to significantly improve the live birth rate in patients with normal ovarian reserve [28]. Taken together, our and previous results strongly indicate that DHEA supplementation can significantly improve the clinical pregnancy and live birth rates and retrieved oocytes.

Although we did not observe significant heterogeneity with regard to the primary outcome, we detected bias in some of the included RCTs. For example, an RCT published by Wiser et al. was limited by an insufficient sample size and use of unsuitable statistical methods (e.g., Fisher's exact test) [34]. Furthermore, patients in the DHEA groups of the included RCTs received a daily DHEA dose of $75 \mathrm{mg}$, whereas previous studies reported that patients with adrenal insufficiency (i.e., DHEA deficiency) experi- 
enced an improvement in well-being at a daily dose of $50 \mathrm{mg}$ DHEA. As DHEA may have androgenic side effects, a lower dose (25-30 mg daily) may be more suitable for the long-term treatment of some patients [44]. The optimal dose of DHEA for the long-term treatment of women with a DOR should be investigated further.

This meta-analysis had some strengths. First, it pooled a large amount of published data from different RCTs, which improves the statistical power. Second, strict methodology was applied, and all included studies were prospectively designed RCTs. Third, no obvious publication bias was detected among these included studies, indicating that the results were unbiased and reliable.

However, this meta-analysis also had several potential limitations. First, although our analysis was based on nine RCTs, some of the trials had relatively small sample sizes. This may have influenced the validity and reliability of our conclusions. Second, although all included studies were RCTs, not all studies described the methods of randomization, blinding, allocation concealment, and missing data treatment. This may have led to performance and reporting biases. Third, the literature search was restricted to studies published in English, which may have biased the pooled effect. Finally, the dosage and duration of DHEA administration were not identical across all of the studies.

Despite these limitations, however, we conclude that the results of this meta-analysis strongly suggest the ability of DHEA supplementation to increase the retrieved oocytes, clinical pregnancy rate, and live birth rate in women with DOR and/or POR who are undergoing IVF/or ICSI.

\section{Conflict of Interest}

The authors declare that they have no conflict of interest.

\section{References}

[1] Gnoth C, Godehardt E, Frank-Herrmann P et al. Definition and prevalence of subfertility and infertility. Hum Reprod 2005; 20: 1144-1147

[2] Broekmans FJ, Soules MR, Fauser BC. Ovarian aging: mechanisms and clinical consequences. Endocr Rev 2009; 30: 465-493

[3] Fouany MR, Sharara FI. Is there a role for DHEA supplementation in women with diminished ovarian reserve? J Assist Reprod Genet 2013; 30 : 1239-1244

[4] Broekmans F], Kwee J, Hendriks DJ et al. A systematic review of tests predicting ovarian reserve and IVF outcome. Hum Reprod Update 2006; 12: 685-718

[5] Broekmans FJ, Faddy M], Scheffer G et al. Antral follicle counts are related to age at natural fertility loss and age at menopause. Menopause 2004; 11: 607-614

[6] Santoro N, Isaac B, Neal-Perry G et al. Impaired folliculogenesis and ovulation in older reproductive aged women. J Clin Endocrinol Metab 2003; 88: 5502-5509

[7] Soules MR, Sherman S, Parrott E et al. Executive summary: Stages of Reproductive Aging Workshop (STRAW). Fertil Steril 2001; 76: 874-878

[8] Templeton A, Morris JK, Parslow W. Factors that affect outcome of in-vitro fertilisation treatment. Lancet 1996; 348: 1402-1406

[9] Menken J, Trussell J, Larsen U. Age and infertility. Science 1986; 233 : 1389-1394
[10] Gleicher N, Weghofer A, Barad DH. Defining ovarian reserve to better understand ovarian aging. Reprod Biol Endocrinol 2011; 9: 23

[11] Trout SW, Seifer DB. Do women with unexplained recurrent pregnancy loss have higher day 3 serum FSH and estradiol values? Fertil Steril 2000; 74: 335-337

[12] Ulug U, Ben-Shlomo I, Turan E et al. Conception rates following assisted reproduction in poor responder patients: a retrospective study in 300 consecutive cycles. Reprod Biomed Online 2003; 6: 439-443

[13] Surrey ES, Schoolcraft WB. Evaluating strategies for improving ovarian response of the poor responder undergoing assisted reproductive techniques. Fertil Steril 2000; 73: 667-676

[14] Tarlatzis BC, Zepiridis L, Grimbizis G et al. Clinical management of low ovarian response to stimulation for IVF: a systematic review. Hum Reprod Update 2003; 9: 61-76

[15] Burger HG. Androgen production in women. Fertil Steril 2002; 77 (Suppl. 4): S3-S5

[16] Casson PR, Lindsay MS, Pisarska MD et al. Dehydroepiandrosterone supplementation augments ovarian stimulation in poor responders: a case series. Hum Reprod 2000; 15: 2129-2132

[17] Triantafyllidou O, Sigalos G, Vlahos N. Dehydroepiandrosterone (DHEA) supplementation and IVF outcome in poor responders. Hum Fertil (Camb) 2017; 20: 80-87

[18] Qin JC, Fan L, Qin AP. The effect of dehydroepiandrosterone (DHEA) supplementation on women with diminished ovarian reserve (DOR) in IVF cycle: Evidence from a meta-analysis. J Gynecol Obstet Hum Reprod 2017; 46: 1-7

[19] Zhang M, Niu W, Wang Y et al. Dehydroepiandrosterone treatment in women with poor ovarian response undergoing IVF or ICSI: a systematic review and meta-analysis. J Assist Reprod Genet 2016; 33: 981-991

[20] Zhang J, Qiu X, Gui Y et al. Dehydroepiandrosterone improves the ovarian reserve of women with diminished ovarian reserve and is a potential regulator of the immune response in the ovaries. Biosci Trends 2015; 9: 350-359

[21] Li J, Yuan H, Chen Y et al. A meta-analysis of dehydroepiandrosterone supplementation among women with diminished ovarian reserve undergoing in vitro fertilization or intracytoplasmic sperm injection. Int J Gynaecol Obstet 2015; 131: 240-245

[22] Nagels HE, Rishworth JR, Siristatidis CS et al. Androgens (dehydroepiandrosterone or testosterone) for women undergoing assisted reproduction. Cochrane Database Syst Rev 2015; (11): CD009749

[23] Urman B, Yakin K. Does dehydroepiandrosterone have any benefit in fertility treatment? Curr Opin Obstet Gynecol 2012; 24: 132-135

[24] Sunkara SK, Pundir J, Khalaf Y. Effect of androgen supplementation or modulation on ovarian stimulation outcome in poor responders: a meta-analysis. Reprod Biomed Online 2011; 22: 545-555

[25] Higgins JP, Altman DG, Gotzsche PC et al. The Cochrane Collaboration's tool for assessing risk of bias in randomised trials. BMJ 2011; 343: d5928

[26] Narkwichean A, Maalouf W, Baumgarten M et al. Efficacy of Dehydroepiandrosterone (DHEA) to overcome the effect of ovarian ageing (DITTO): A proof of principle double blinded randomized placebo controlled trial. Eur J Obstet Gynecol Reprod Biol 2017; 218: 39-48

[27] Kotb MM, Hassan AM, AwadAllah AM. Does dehydroepiandrosterone improve pregnancy rate in women undergoing IVF/ICSI with expected poor ovarian response according to the Bologna criteria? A randomized controlled trial. Eur J Obstet Gynecol Reprod Biol 2016; 200: 11-15

[28] Tartagni M, Cicinelli MV, Baldini D et al. Dehydroepiandrosterone decreases the age-related decline of the in vitro fertilization outcome in women younger than 40 years old. Reprod Biol Endocrinol 2015; 13: 18

[29] Zhang HH, Xu PY, Wu J et al. Dehydroepiandrosterone improves follicular fluid bone morphogenetic protein-15 and accumulated embryo score of infertility patients with diminished ovarian reserve undergoing in vitro fertilization: a randomized controlled trial. J Ovarian Res 2014; 7: 93 
[30] Yeung TW, Chai ], Li RH et al. A randomized, controlled, pilot trial on the effect of dehydroepiandrosterone on ovarian response markers, ovarian response, and in vitro fertilization outcomes in poor responders. Fertil Steril 2014; 102: 108-115.e1

[31] Kara M, Aydin T, Aran T et al. Does dehydroepiandrosterone supplementation really affect IVF-ICSI outcome in women with poor ovarian reserve? Eur J Obstet Gynecol Reprod Biol 2014; 173: 63-65

[32] Moawad A, Shaeer M. Long-term androgen priming by use of dehydroepiandrosterone (DHEA) improves IVF outcome in poor-responder patients. A randomized controlled study. Middle East Fertil Soc J 2012; 17 : $268-274$

[33] Artini PG, Simi G, Ruggiero M et al. DHEA supplementation improves follicular microenviroment in poor responder patients. Gynecol Endocrinol 2012; 28: 669-673

[34] Wiser A, Gonen O, Ghetler Y et al. Addition of dehydroepiandrosterone (DHEA) for poor-responder patients before and during IVF treatment improves the pregnancy rate: a randomized prospective study. Hum Reprod 2010; 25: 2496-2500

[35] Narkwichean A, Maalouf W, Campbell BK et al. Efficacy of dehydroepiandrosterone to improve ovarian response in women with diminished ovarian reserve: a meta-analysis. Reprod Biol Endocrinol 2013; 11: 44

[36] Barad DH, Gleicher N. Increased oocyte production after treatment with dehydroepiandrosterone. Fertil Steril 2005; 84: 756

[37] Barad D, Gleicher N. Effect of dehydroepiandrosterone on oocyte and embryo yields, embryo grade and cell number in IVF. Hum Reprod 2006; 21: 2845-2849
[38] Gleicher N, Ryan E, Weghofer A et al. Miscarriage rates after dehydroepiandrosterone (DHEA) supplementation in women with diminished ovarian reserve: a case control study. Reprod Biol Endocrinol 2009; 7: 108

[39] Sonmezer M, Ozmen B, Cil AP et al. Dehydroepiandrosterone supplementation improves ovarian response and cycle outcome in poor responders. Reprod Biomed Online 2009; 19: 508-513

[40] Harper AJ, Buster JE, Casson PR. Changes in adrenocortical function with aging and therapeutic implications. Semin Reprod Endocrinol 1999; 17: 327-338

[41] Gleicher N, Kim A, Weghofer A et al. Hypoandrogenism in association with diminished functional ovarian reserve. Hum Reprod 2013; 28: 1084-1091

[42] Hillier SG, Whitelaw PF, Smyth CD. Follicular oestrogen synthesis: the 'two-cell, two-gonadotrophin' model revisited. Mol Cell Endocrinol 1994; 100: 51-54

[43] Casson PR, Santoro N, Elkind-Hirsch K et al. Postmenopausal dehydroepiandrosterone administration increases free insulin-like growth factor-I and decreases high-density lipoprotein: a six-month trial. Fertil Steril 1998; 70: 107-110

[44] Arlt W, Callies F, van Vlijmen JC et al. Dehydroepiandrosterone replacement in women with adrenal insufficiency. N Engl J Med 1999; 341: 1013-1020 